\title{
Duodenal intraepithelial lymphocytosis with normal villous architecture: common occurrence in $\boldsymbol{H}$. pylori gastritis
}

\author{
Lorenzo Memeo $^{1}$, Jeffrey Jhang ${ }^{1}$, Hanina Hibshoosh ${ }^{1}$, Peter H Green ${ }^{2}$, Heidrun Rotterdam \\ and Govind Bhagat ${ }^{1}$ \\ ${ }^{1}$ Department of Pathology, College of Physicians and Surgeons, Columbia University Medical Center, \\ New York, NY, USA and ${ }^{2}$ Department of Gastroenterology, College of Physicians and Surgeons, Columbia \\ University Medical Center, New York, NY, USA
}

\begin{abstract}
We have observed expansions of intraepithelial lymphocytes in duodenal biopsies from patients with Helicobacter pylori gastritis. This study was undertaken to prospectively evaluate, unselected, paired gastric and duodenal biopsies from 50 patients with $\mathrm{H}$. pylori gastritis and a comparison group of 30 patients with other types of gastritis (10 autoimmune and 20 reactive) to: (1) quantify duodenal intraepithelial lymphocytes, determine their distribution patterns, epithelial location, and phenotype, and (2) correlate the intraepithelial lymphocyte elevations with various features of gastric and duodenal pathology. Intraepithelial lymphocytes were analyzed with antibodies including CD3, CD8, and TIA-1. A stain for $\boldsymbol{H}$. pylori was performed on all gastric and duodenal biopsies. Duodenal intraepithelial lymphocytes from patients with $H$. pylori gastritis (using CD3) ranged from 3 to 42 lymphocytes/100 epithelial cells (mean 18.5) compared to 3 to 18 lymphocytes/100 epithelial cells (mean 6.6) in the comparison group. Intraepithelial lymphocyte elevations were seen in $44 \%$ of the duodenal biopsies from patients with $\boldsymbol{H}$. pylori gastritis (using CD3). Significant differences in the intraepithelial lymphocyte counts between patients with $H$. pylori gastritis and the comparison group were seen for all three T-cell antigens $(\boldsymbol{P}<0.001$ for CD3 and CD8 and $\boldsymbol{P}<0.002$ for TIA-1). Duodenal intraepithelial lymphocytes in the H. pylori + cases had a latent cytotoxic phenotype, $H$. pylori was not visualized in any of the duodenal biopsies from patients with $\boldsymbol{H}$. pylori gastritis, and no patient had clinical evidence of celiac disease. Our study highlights frequent duodenal intraepithelial lymphocytosis in individuals with $H$. pylori gastritis and the lymphocyte distribution patterns (and numbers) overlapped with those described for celiac disease patients. $\mathrm{H}$. pylori gastritis must be considered as a possible explanation for duodenal intraepithelial lymphocytosis with normal villous architecture, especially when lymphocytosis is patchy, intraepithelial lymphocytes display a 'latent' cytotoxic phenotype, and the clinical findings and serologic profile does not fit celiac disease.
\end{abstract}

Modern Pathology (2005) 18, 1134-1144. doi:10.1038/modpathol.3800404; published online 1 April 2005

Keywords: H. pylori; intraepithelial lymphocytosis; duodenum

Helicobacter pylori, a Gram negative bacterium, is one of the most prevalent human pathogens, infecting up to $30 \%$ of individuals in developed countries $^{1}$ and $>50 \%$ of the population in developing countries, ${ }^{2}$ making $H$. pylori gastritis the most common infectious disease worldwide. ${ }^{3}$ Infected individuals most commonly develop nonatrophic pan-gastritis. Duodenal ulcer disease is uncommon

Correspondence: Dr G Bhagat, MD, OVC14-236, Department of Pathology, College of Physicians and Surgeons, Columbia University Medical Center, 630 W168th Street, New York, NY, 10032, USA. E-mail: gb96@columbia.edu

Received 3 September 2004; revised 12 January 2005; accepted 13 January 2005; published online 1 April 2005 in individuals with this pattern of gastritis but occurs more often in people with antral predominant gastritis. ${ }^{4}$ Other patterns of $H$. pylori gastritis, including lymphocytic gastritis, are also well recognized. ${ }^{5} \mathrm{H}$. pylori is responsible for $90-95 \%$ of all cases of duodenitis, ${ }^{6}$ histologically characterized as either ulcer-associated or nonspecific. Duodenal biopsies from patients with $H$. pylori gastritis, taken from areas of erythema or endoscopically normalappearing mucosa, demonstrate a variable expansion of the lamina propria due to an increase in the number of plasma cells, lymphocytes, and macrophages. Neutrophillic infiltrates are seen occasionally, but foci of gastric metaplasia, with or without $H$. pylori colonization, are only rarely identified due to their patchy distribution. ${ }^{7}$ 
While evaluating duodenal biopsies from patients with $H$. pylori gastritis, we have observed increased numbers of intraepithelial lymphocytes in a significant number of cases that had no alterations of villous architecture. Moreover, differentiating the various patterns of lymphocytic infiltrates, in many of these cases, from those observed in celiac disease and other small bowel diseases, was not possible on $\mathrm{H} \& \mathrm{E}$ examination. Proximal small bowel intraepithelial lymphocytosis is most commonly observed in biopsies from patients with celiac disease, often accompanied by alterations of the villous architecture. ${ }^{8}$ Increasing awareness of a high prevalence of celiac disease in the West, including the United States, ${ }^{9}$ has led to both an increase in the number of small bowel biopsies performed by gastroenterologists, as well as a heightened sensitivity of pathologists to detect subtle architectural alterations of the duodenal mucosa. Numerous studies, over the past decade, have highlighted the frequent finding of isolated duodenal intraepithelial lymphocytosis with minimal or no villous architectural alterations, described as the 'infiltrative lesion' (Marsh stage 1) by Marsh and Crowe, ${ }^{10}$ as the sole abnormality, in biopsies from celiac disease patients. ${ }^{11,12}$ Even though duodenal (or jejunal) intraepithelial lymphocytosis, as an isolated finding, has a high sensitivity for celiac disease, it lacks sufficient specificity for this entity, as elevations of intraepithelial lymphocytes are observed in a variety of gastrointestinal (and extra-intestinal) diseases (Table 1).

Surgical pathologists commonly encounter duodenal biopsies from individuals with $H$. pylori gastritis but there is a paucity of information regarding the incidence, extent, phenotype, or the pattern of intraepithelial lymphocytes that can be observed in these biopsies. We carried out a prospective study that entailed: quantifying duodenal intraepithelial lymphocytes, determining their patterns of distribution (villous-tip, villous-base, or uniform) and epithelial location (supranuclear, subnuclear, or both), phenotypic characteristics, and correlating intraepithelial lymphocyte elevations

Table 1 Etiology of increased duodenal intraepithelial lymphocytes in the absence of gluten sensitivity

\begin{tabular}{|c|c|}
\hline Etiology & Reference \\
\hline Food allergy & Mavromichalis et $a l^{53}$ \\
\hline $\begin{array}{l}\text { Primary immunodeficiency } \\
\text { diseases }\end{array}$ & Klemola, ${ }^{54}$ Nilsen et $a l^{55}$ \\
\hline Viral enteritis & Goldstein, ${ }^{28}$ Cutz et al ${ }^{61}$ \\
\hline Giardiasis & Mavromichalis et $a l^{53}$ \\
\hline Blind loop syndrome & Burrows et $a l^{56}$ \\
\hline Tropical (postinfectious) sprue ${ }^{\mathrm{a}}$ & Ansari $^{57}$ \\
\hline Crohn's disease & Wright and Riddell ${ }^{58}$ \\
\hline Autoimmune diseases & Kakar et $a l^{15}{ }^{15}$ Holden et $a l^{60}$ \\
\hline NSAIDS & Kakar et al ${ }^{15}$ \\
\hline Irritable bowel disease & Tornblon et a ${ }^{59}$ \\
\hline
\end{tabular}

${ }^{\mathrm{a}}$ Usually in distal small bowel. with various gastric and duodenal histologic parameters in patients with $H$. pylori gastritis. Duodenal intraepithelial lymphocyte counts were also performed in other types of gastritis (reactive and autoimmune) for comparison. We discuss the patterns of intraepithelial lymphocyte distribution and their phenotype, in relation to those reported for celiac disease ${ }^{13,14}$ and other small intestinal diseases, ${ }^{15,16}$ to highlight similarities as well as differences.

\section{Materials and methods}

\section{Tissue Samples and Patient Characteristics}

We evaluated 50 consecutive, unselected, paraffinembedded, formalin-fixed $(10 \%$ neutral-buffered formalin) paired gastric antral and duodenal biopsies from patients with $H$. pylori gastritis $(19 \mathrm{M}, 31 \mathrm{~F}$, age range 27-81 years, mean 58 years) and 30 unselected, and paired gastric antral and duodenal biopsies from patients (16 M, $24 \mathrm{~F}$, age range 15-83 years, mean 54 years) with other forms of gastritis (10 cases of autoimmune gastritis and 20 cases of reactive gastritis, including five with an acute inflammatory component). In 32 cases (64\%) of $H$. pylori gastritis, fundus/body biopsies were also available for review. The duodenal biopsies were taken from areas of erythema, mucosal nodularity, or endoscopically normal mucosa. Clinical information regarding associated gastrointestinal (and nonGI) symptoms and conditions, and history of NSAID use were obtained from the hospital information system. There was no clinical evidence of giardiasis or any other parasitic infection, celiac disease, or food allergy in any of the patients with $H$. pylori gastritis. Serologic testing, for endomysial or tissue transglutaminase antibodies, prompted by the histologic findings, was performed in four patients.

\section{Immunohistochemistry}

An initial subset of duodenal biopsies $(n=20)$ from patients with $(n=10)$ and without $(n=10) H$. pylori infection were stained with the antibodies listed (Table 2) to: (1) characterize the intraepithelial and lamina propria lymphocytes and (2) detect any phenotypic alterations of the epithelium. The remaining cases were only stained with antibodies against CD3, CD8, TIA-1, and $H$. pylori. Briefly, $4 \mu \mathrm{m}$ formalin-fixed, paraffin-embedded sections were deparaffinized and subjected to antigen retrieval (10 mM citrate buffer $(\mathrm{pH} 6)$ and microwaved for $25 \mathrm{~min}$ ). Immunohistochemical staining was performed on a Dako autostainer (Dako, Carpinteria, CA, USA). Slides were incubated with the primary antibodies ( $30 \mathrm{~min}$, room temperature) and detection was carried out using the Envision plus system (Dako, Carpinteria, CA, USA) with DAB as 
Table 2 Primary antibodies used for immunohistochemical analysis

\begin{tabular}{|c|c|c|c|}
\hline Antibody & Clone & Dilution & Supplier \\
\hline CD3 & F7.2.38 & $1: 800$ & $\begin{array}{l}\text { Dako, Carpinteria, } \\
\text { CA, USA }\end{array}$ \\
\hline CD20 & L26 & $1: 500$ & $\begin{array}{l}\text { Dako, Carpinteria, } \\
\text { CA, USA }\end{array}$ \\
\hline CD8 & C8/144B & $1: 40$ & $\begin{array}{l}\text { Dako, Carpinteria, } \\
\text { CA, USA }\end{array}$ \\
\hline CD45 & $\begin{array}{l}\mathrm{PD} 7 / 26 \\
\text { and 2B11 }\end{array}$ & $1: 200$ & $\begin{array}{l}\text { Dako, Carpinteria, } \\
\text { CA, USA }\end{array}$ \\
\hline CD4 & $4 \mathrm{BI} 2$ & $1: 50$ & $\begin{array}{l}\text { Novocastra, Burlingame, } \\
\text { CA, USA }\end{array}$ \\
\hline TIA-1 & 2G9A10F5 & 1:1000 & $\begin{array}{l}\text { Immunotech, Westbrook, } \\
\text { ME, USA }\end{array}$ \\
\hline E-cadherin & 36B5 & $1: 40$ & $\begin{array}{l}\text { Chemicon, Temecula, } \\
\text { CA, USA }\end{array}$ \\
\hline MIB-1 & KI-S5 & $1: 50$ & $\begin{array}{l}\text { Dako, Carpinteria, } \\
\text { CA, USA }\end{array}$ \\
\hline Perforin & $5 \mathrm{~B} 10$ & $1: 50$ & $\begin{array}{l}\text { Novocastra, Burlingame, } \\
\text { CA, USA }\end{array}$ \\
\hline Granzyme B & GrB7 & $1: 20$ & $\begin{array}{l}\text { Chemicon, Temecula, } \\
\text { CA, USA }\end{array}$ \\
\hline $\begin{array}{l}\text { Helicobacter } \\
\text { pylori }\end{array}$ & & 1:10 & $\begin{array}{l}\text { Abcam, Cambridge, } \\
\text { MA, USA }\end{array}$ \\
\hline
\end{tabular}

chromogen. Positive controls consisted of sections of tonsil and normal small bowel.

\section{Biopsy Assessment and Scoring}

Semiquantitative scoring ( 1 to $3+)$ of gastric biopsies was performed according to the revised Sydney criteria ${ }^{17}$ in addition to other parameters, including: (1) presence of lymphoid follicles, (2) extent of intestinal metaplasia ( 0 to $3+$ ), (3) density of $H$. pylori organisms $(1+$ to $3+)$, and (4) number of lymphocytes/100 epithelial cells, an upper limit of 25 lymphocytes/100 epithelial cells was considered normal. ${ }^{16}$ Duodenal biopsies were assessed for: (1) grade of acute and chronic inflammation, (2) presence of $H$. pylori, (3) presence of lymphoid follicles, (4) villous atrophy, (5) crypt hyperplasia, (6) gastric metaplasia, and (7) number of lymphocytes/100 epithelial cells, an upper limit of 20 lymphocytes/100 epithelial cells was considered normal. ${ }^{13}$ Biopsy pieces with the highest number of lymphocytes were chosen to calculate the intraepithelial lymphocyte counts, as these tend to catch the attention of pathologists and are used for a subjective estimation of intraepithelial lymphocytosis. Intraepithelial lymphocyte quantification was performed on serial sections stained with CD3, CD8, and TIA-1. The number of intraepithelial lymphocytes was assessed in five different villi by counting the number of lymphocytes/100 epithelial cells in each villus, and calculating the mean. Predominant distribution (villous-base, villous-tip, or even distribution along the villous-length) and epithelial location (supranuclear, subnuclear, or both supra and subnuclear) of the lymphocytes was noted. The percentage of villi/biopsy piece with increased intraepithelial lymphocytes was also assessed and data segregated into four groups: 0-25, 26-50, 51-75, and 75-100\%. All duodenal biopsies had at least two well-oriented pieces (range 2-9, mean 3.12) where villous architecture could be evaluated.

\section{Statistics}

Fisher's exact test and $\chi^{2}$ tests were performed and $P<0.05$ was considered significant.

\section{Results}

\section{Immunohistochemistry}

In the initial subset of duodenal biopsies (20 cases), the majority of lamina propria T cells were CD4+ and only rare $\mathrm{CD} 4+\mathrm{T}$ cells were seen in the epithelium. The intraepithelial lymphocytes were: CD3 + , CD8 + , and TIA-1 + (Figures 1 and 2); only a few lymphocytes stained (weakly) with perforin or granzyme B, consistent with a 'latent cytotoxic' phenotype. CD20 highlighted scattered B cells and lymphoid follicles in the lamina propria. Rare intraepithelial lymphocytes stained with MIB-1 in duodenal biopsies from both groups and no difference in the proliferation rates was noted between the two groups. No alteration in the pattern of E-cadherin staining was detected (membranous in all cases). Immunohistochemical staining for $H$. pylori identified the bacillus in all antral but none of the duodenal biopsies from patients with $H$. pylori gastritis. In addition, $H$. pylori was not identified in any of the gastric or duodenal biopsies from patients with other forms of gastritis.

\section{Intraepithelial Lymphocyte Counts and Distribution}

Duodenal intraepithelial lymphocytes (on CD3stained sections) from patients with $H$. pylori gastritis ranged from 3 to 45 lymphocytes/100 epithelial cells (mean 18.5) compared to a range of 3 to 18 lymphocytes/100 epithelial cells (mean 6.6) in patients with other types of gastritis. Significant differences in the intraepithelial lymphocyte counts were observed between patients with $H$. pylori gastritis and other forms of gastritis for all three T-cell antigens $(P<0.001$ for CD3 and CD8 and $P<0.002$ for TIA-1). Increased numbers of intraepithelial lymphocytes were documented in $44 \%$ of the duodenal biopsies of patients with $H$. pylori gastritis on staining for CD3, 46\% with CD8, and $42 \%$ with TIA-1. These differences were statistically nonsignificant; most likely reflecting a sampling variation due to scoring of different levels with the different antibodies (Table 3). Intraepithelial lymphocyte elevations limited to $<25 \%$ of the villi were 

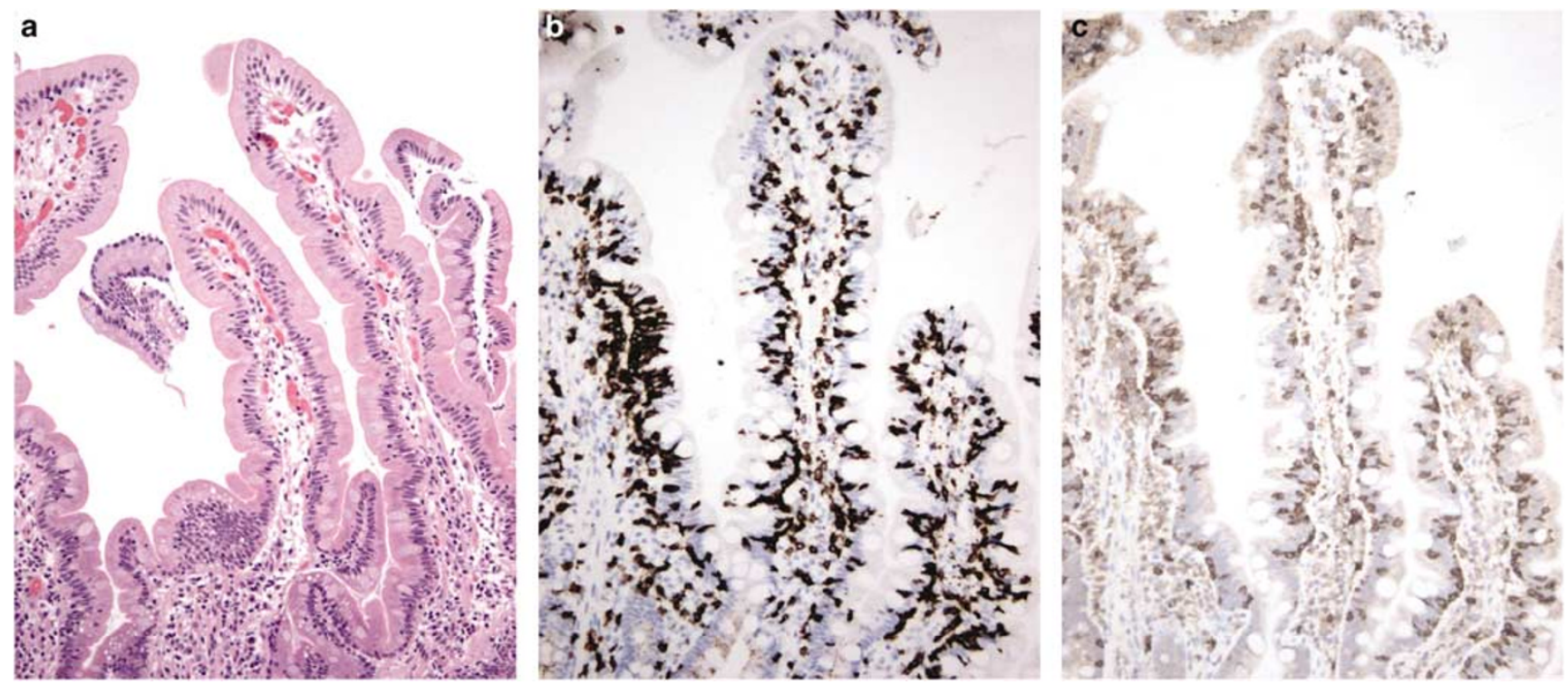

Figure 1 An example of an even distribution pattern of intraepithelial lymphocytes along the length of an architecturally normal villous: (a) H\&E, (b) CD3, (c) CD8 (all $\times 10)$.

observed in only one biopsy while increased intraepithelial lymphocytes involving $>75 \%$ of villi were seen in 10 biopsies $(20 \%)$. Data regarding the percentage of villi/biopsy-piece with increased intraepithelial lymphocytes are provided in Table 4. There was no singular, predominant pattern of intraepithelial lymphocyte distribution along the crypt-villus axis (Table 5). No statistical difference was found between a basal or villous-tip predominant pattern (36 vs 22\%). An even distribution of intraepithelial lymphocytes, along the villous length, was as common as a basal predominant pattern. Figure 1 and $2 \mathrm{~b}$ represent examples of the diffuse or even distribution pattern of intraepithelial lymphocytes while Figure 2a illustrates the villoustip predominant pattern. Superficial/supranuclear location of the intraepithelial lymphocytes was as common as a subnuclear location, the majority of cases, however, showed an equal distribution of lymphocytes in these two locations (Table 6). An example of the latter pattern is shown in Figure $2 \mathrm{~b}$.

\section{Correlation of Duodenal Intraepithelial Lymphocytes with Duodenal and Gastric Pathology}

The majority of patients, 42/50 (84\%), had antral predominant gastritis and only $8 / 50(16 \%)$ had evidence of pan-gastritis. The number of duodenal intraepithelial lymphocytes did not correlate with the density and location (antrum, body, or both) of $H$. pylori in the gastric mucosa, severity of acute or chronic inflammation of the gastric antrum or duodenum, presence of gastric mucosal lymphoid follicles, or the presence of intestinal metaplasia in the stomach. The gastric antrum had $<25$ lymphocytes/100 epithelial cells (range 2-9 lymphocytes/
100 epithelial cells, mean 4 lymphocytes/100 epithelial cells) in all cases of $H$. pylori gastritis. No formal count was performed in biopsies from the body/fundus as only rare intraepithelial lymphocytes were identified in this location. The villuscrypt ratio was $>3: 1$ in all duodenal biopsies and no villous blunting, mucin depletion, or gastric metaplasia was identified in any of the duodenal biopsies from patients with $H$. pylori gastritis or the comparison group. Scattered neutrophils were seen in the duodenal lamina propria (but not the surface epithelium) in only $4 / 50$ (8\%) biopsies from patients with $H$. pylori gastritis and in none of the biopsies from the comparison group. Lymphoid follicles or aggregates were present in 7/50 (14\%) of duodenal biopsies from patients with $H$. pylori gastritis but in none of the biopsies from the control group. There was no histologic evidence of Crohn's disease, giardiasis, or food allergy in duodenal biopsies from both groups. No significant differences, in the severity of duodenal inflammation, were observed between the two groups.

\section{Patient Characteristics}

No significant differences were noted regarding other gastrointestinal (as well as non GI) symptoms and conditions between the two groups (Table 7). A history of NSAID use was only documented in a minority of patients with $H$. pylori gastritis $(10 \%)$ but in none of the patients from the comparison group. Owing to the nature of associated diseases or medical conditions, it is likely that use of antiinflammatory agents was under-reported in both patient groups. The results of serologic testing for celiac disease were negative in all four patients 
a

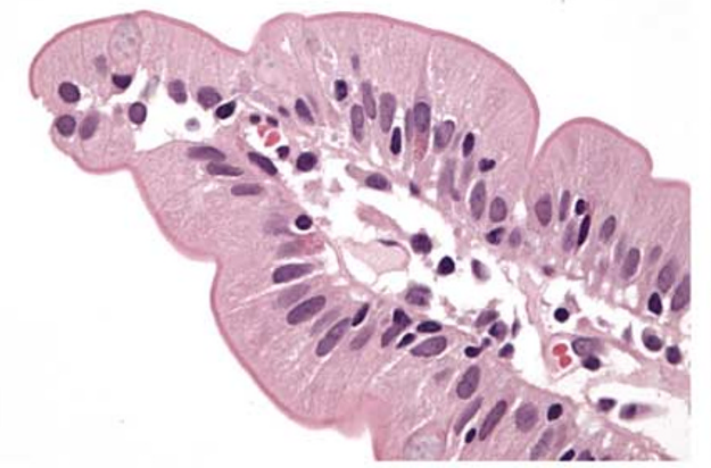

c
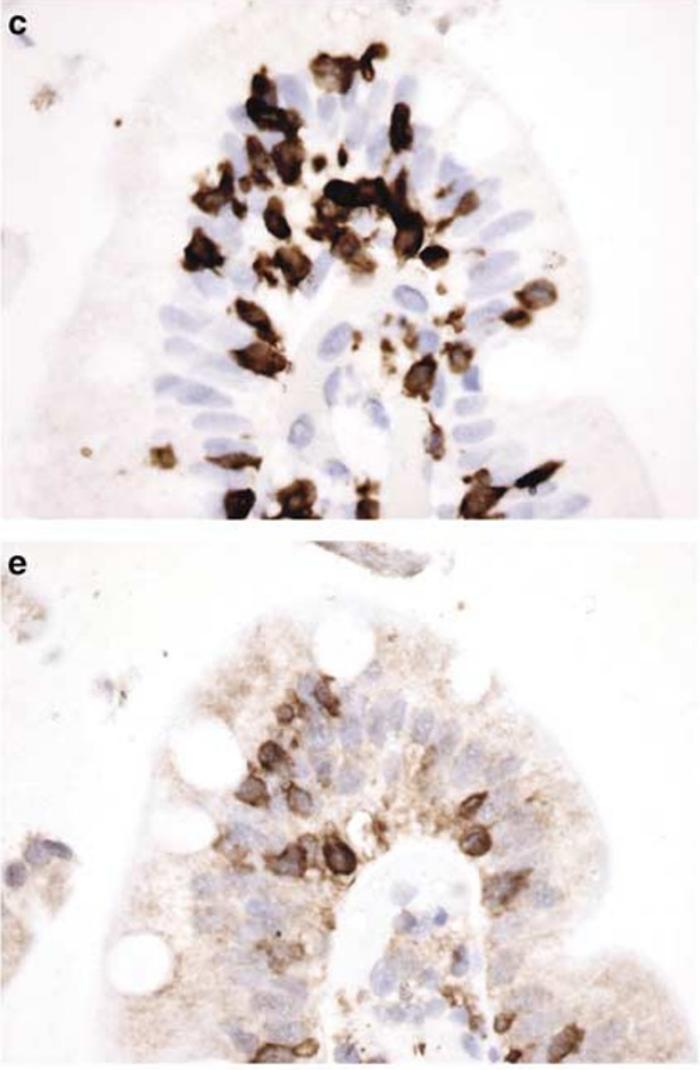

g b

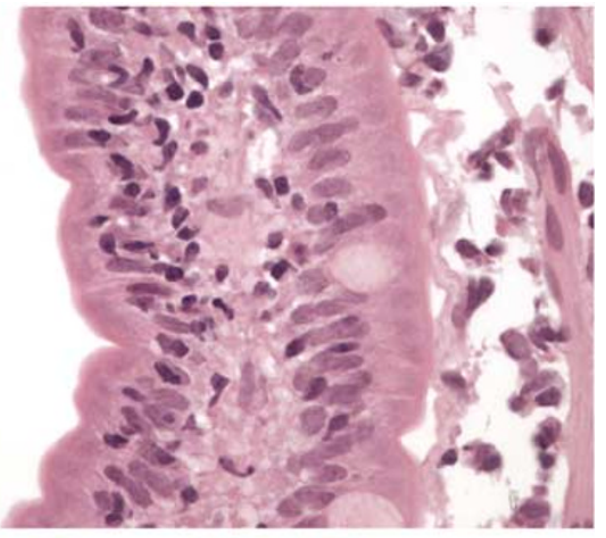

d

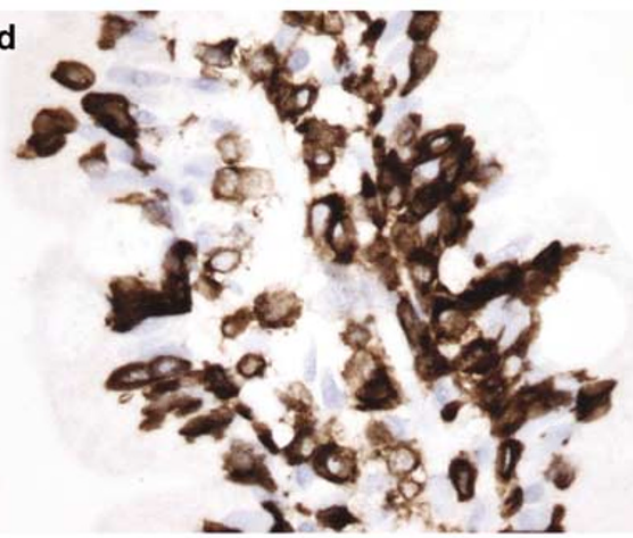

f

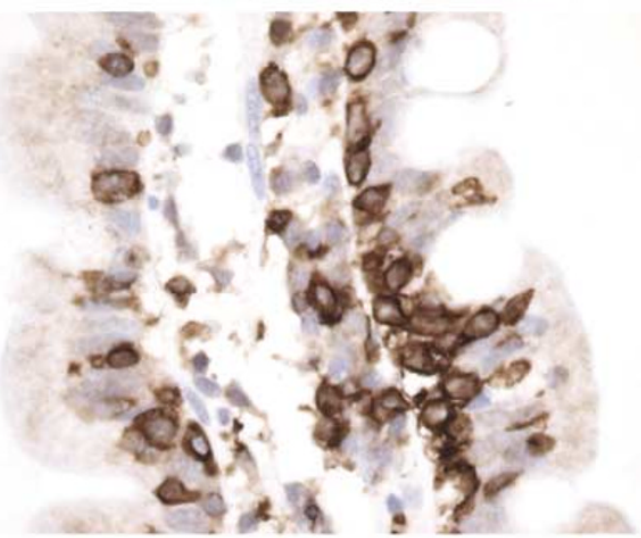

h

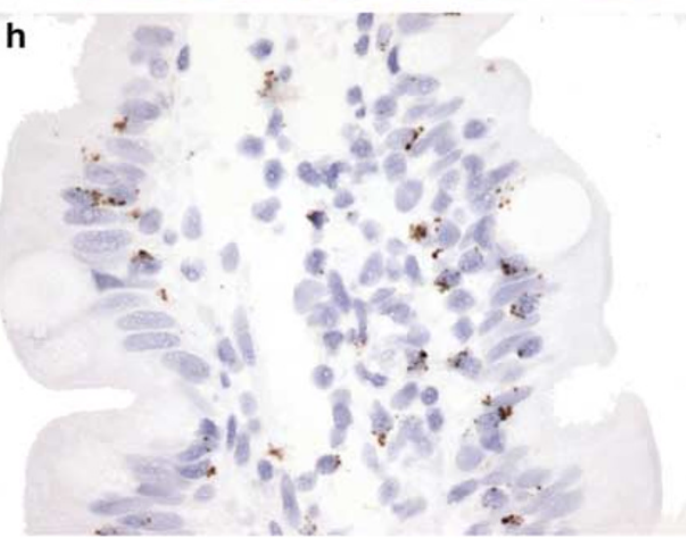

Figure 2 (a) Increased intraepithelial lymphocytes present in the villous tip. Intraepithelial lymphocytes stain with (c) CD3, (e) CD8, and (g) TIA-1. (b) Intraepithelial lymphocyte distribution along the villous edge; lymphocytes are present in both supranuclear and subnuclear locations, (d) CD3, (f) CD8, and (h) TIA-1 (all $\times 40$ ). 
Table 3 Duodenal intraepithelial lymphocyte elevations in $H$. pylorit cases

\begin{tabular}{lrcc}
\hline & $20-25 / 100 E C$ & $26-30 / 100 E C$ & $>30 / 100 E C$ \\
\hline CD3 $(n=22)$ & 8 & 8 & 6 \\
CD8 $(n=23)$ & 12 & 6 & 5 \\
TIA-1 $(n=21)$ & 9 & 8 & 4 \\
\hline
\end{tabular}

EC, epithelial cells.

Table 4 Percentage of villi with increased intraepithelial lymphocytes in $H$. pylorit cases

\begin{tabular}{lccrr}
\hline & $0-25 \%$ & $26-50 \%$ & $51-75 \%$ & $76-100 \%$ \\
\hline CD3+ $(n=22)$ & 1 & 5 & 6 & 10 \\
CD8+ $(n=23)$ & 0 & 4 & 10 & 9 \\
TIA-1+ $(n=21)$ & 1 & 6 & 8 & 6 \\
\hline
\end{tabular}

Table 5 Intraepithelial lymphocyte distribution along the cryptvillous axis in $H$. pylori+ cases

\begin{tabular}{llll}
\hline & Base & Tip & Both \\
\hline CD3 $(n=22)$ & 8 cases & 5 cases & 9 cases \\
CD8 $(n=23)$ & 9 cases & 6 cases & 8 cases \\
TIA-1 $(n=21)$ & 8 cases & 5 cases & 8 cases \\
\hline
\end{tabular}

Table 6 Epithelial location of lymphocytes in H. pylori+ cases

\begin{tabular}{llll}
\hline & $\begin{array}{l}\text { Basal/ } \\
\text { subnuclear }\end{array}$ & $\begin{array}{l}\text { Superficial/ } \\
\text { supranuclear }\end{array}$ & $\begin{array}{l}\text { Basal and } \\
\text { superficial }\end{array}$ \\
\hline $\begin{array}{l}\text { CD3 } \\
(n=22)\end{array}$ & 7 cases & 5 cases & 10 cases \\
$\begin{array}{l}\text { CD8 } \\
(n=23)\end{array}$ & 8 cases & 6 cases & 9 cases \\
$\begin{array}{l}\text { TIA-1 } \\
(n=21)\end{array}$ & 6 cases & 4 cases & 11 cases \\
\hline
\end{tabular}

tested. None of the patients were referred to the celiac disease clinic due to resolution of symptoms post triple drug therapy for $H$. pylori. Post-therapy duodenal biopsies were not performed.

\section{Discussion}

The triad of villous atrophy, intraepithelial lymphocytosis, and chronic inflammation of the duodenum has been referred to as the 'celiac lesion.' These histologic features are considered the 'gold standard' for diagnosing celiac disease or gluten-sensitive enteropathy. ${ }^{18}$ Fry et $a l,{ }^{19}$ more than three decades ago, had brought attention to the diagnostic
Table 7 Associated symptoms, signs, and diseases in patients with $H$. pylori and other types of gastritis

\begin{tabular}{|c|c|c|c|}
\hline & $\begin{array}{c}\text { H. pylori+ cases } \\
\text { with } \\
\text { intraepithelial } \\
\text { lymphocytosis }\end{array}$ & $\begin{array}{c}\text { H. pylori+ cases } \\
\text { without } \\
\text { intraepithelial } \\
\text { lymphocytosis }\end{array}$ & $\begin{array}{c}\mathrm{H} . \\
\text { pylori- } \\
\text { cases }\end{array}$ \\
\hline \multicolumn{4}{|c|}{ GI symptoms/conditions } \\
\hline $\begin{array}{l}\text { Abdominal or } \\
\text { epigastric pain }\end{array}$ & 13 & 7 & 11 \\
\hline Diarrhea & 1 & 5 & 5 \\
\hline Dyspepsia & 0 & 3 & 5 \\
\hline GE reflux & 1 & 2 & 3 \\
\hline Anemia & 2 & 4 & 2 \\
\hline $\begin{array}{l}\text { Irritable bowel } \\
\text { disease }\end{array}$ & 1 & 1 & 0 \\
\hline $\begin{array}{l}\text { History of } \\
\text { Crohn disease }\end{array}$ & 1 & 0 & 1 \\
\hline $\begin{array}{l}\text { History of } \\
\text { duodenal } \\
\text { ulcer }\end{array}$ & 1 & 1 & 0 \\
\hline $\begin{array}{l}\text { History of } \\
\text { colon cancer } \\
\text { or polyps }\end{array}$ & 2 & 4 & 3 \\
\hline $\begin{array}{l}\text { History of } \\
\text { pancreatitis }\end{array}$ & 0 & 1 & 0 \\
\hline \multicolumn{4}{|c|}{ Other diseases/conditions } \\
\hline Hematemesis & 0 & 1 & 0 \\
\hline Arthritis & 1 & 2 & 1 \\
\hline HIV & 0 & 1 & 0 \\
\hline $\begin{array}{l}\text { Nephrotic } \\
\text { syndrome }\end{array}$ & 0 & 0 & 1 \\
\hline $\begin{array}{l}\text { Cardiovascular } \\
\text { disease }\end{array}$ & 2 & 3 & 0 \\
\hline Diabetes & 0 & 1 & 0 \\
\hline Asthma & 1 & 1 & 0 \\
\hline $\begin{array}{l}\text { History of } \\
\text { neurologic } \\
\text { disease }\end{array}$ & 0 & 0 & 1 \\
\hline $\begin{array}{l}\text { History of } \\
\text { breast } \\
\text { cancer }\end{array}$ & 0 & 0 & 1 \\
\hline $\begin{array}{l}\text { History of } \\
\text { prostate } \\
\text { cancer }\end{array}$ & 1 & 0 & 1 \\
\hline $\begin{array}{l}\text { History of } \\
\text { GYN cancer }\end{array}$ & 0 & 1 & 0 \\
\hline $\begin{array}{l}\text { History of } \\
\text { Hodgkin's } \\
\text { lymphoma }\end{array}$ & 1 & 0 & 0 \\
\hline
\end{tabular}

significance of increased intraepithelial lymphocytes in patients with celiac disease. Intraepithelial lymphocytosis was found to be more reliable in detecting gluten sensitivity than the endoscopic appearance of small bowel mucosa. An increase in jejunal intraepithelial lymphocytes is one of the earliest histologic abnormalities in response to gluten challenge before any epithelial and structural alterations are noted. ${ }^{20,21}$ Duodenal biopsies from patients with the 'silent' or latent celiac disease, ${ }^{22}$ dermatitis herpetiformis, ${ }^{23}$ and first-degree relatives of patients with celiac disease ${ }^{24}$ often show isolated intraepithelial lymphocytosis. Even biopsies from symptomatic patients, at times, demonstrate increased intraepithelial lymphocytes as the sole 
mucosal abnormality. ${ }^{12,14}$ Recent studies have, however, reported a low specificity of 'isolated intraepithelial lymphocytosis' for diagnosing celiac disease. ${ }^{13,15,25,26}$ This is not surprising as numerous etiologic agents can elicit an increase in duodenal intraepithelial lymphocytes, in association with a spectrum of mucosal changes that mimic celiac disease $^{15,26-28}$ (Table 1).

Hasan et $a l^{29}$ reported increased intraepithelial lymphocytes in association with both ulcer-associated and nonspecific duodenitis in 1983, prior to the discovery of $H$. pylori as the major etiologic agent. They found significantly higher intraepithelial lymphocyte counts in biopsies from areas of duodenal ulceration and severe nonspecific duodenitis, compared to controls. Hayat et $a l^{30}$ found raised intraepithelial lymphocyte counts, in the second part of the duodenum, in 4/13 (31\%) patients with $H$. pylori-associated lymphocytic gastritis. Gastric intraepithelial lymphocyte counts decreased after treatment of $H$. pylori infection but the duodenal intraepithelial lymphocytosis persisted. The authors suggested the possibility of underlying celiac disease in these patients $(2 / 4$ patients had villous atrophy and $70 \%$ possessed the HLA-DQ2 allele).

We observed a high rate of duodenal intraepithelial lymphocytosis (44\%, using CD3) in patients with $H$. pylori gastritis who had otherwise normal villous architecture (Figure 1, Table 3). Intraepithelial lymphocytosis was patchy but 16/22 (73\%) biopsies (using CD3) had increased intraepithelial lymphocytes in $>50 \%$ of villi/biopsy piece (Table 4). A villous-base predominant or diffuse pattern of lymphocyte distribution was more commonly observed but a villous-tip predominant pattern (Figure 2) was seen in $23 \%$ of cases (Table 5). In contrast to Hasan et $a l,{ }^{29}$ who described a subnuclear location of intraepithelial lymphocytes in the three cases (200 cell count) analyzed, we observed all three patterns: subnuclear $(32 \%)$, supranuclear $(23 \%)$, and mixed $(45 \%)$.

Duodenal biopsies from patients with celiac disease often show a uniform distribution of intraepithelial lymphocytes. Goldstein and Underhill $^{14}$ found a high sensitivity but a low specificity of the 'even intraepithelial lymphocyte distribution pattern' for celiac disease. The extent of duodenal intraepithelial lymphocytosis is also not helpful in making the distinction between celiac disease and other small bowel diseases with increased intraepithelial lymphocytes. ${ }^{13}$ Intraepithelial lymphocyte expansions in celiac disease can occasionally be patchy ${ }^{31-33}$ that is, only one or a few biopsy pieces have increased intraepithelial lymphocytes. A top heavy or villous-tip predominant pattern of intraepithelial lymphocyte distribution, with the loss of the 'decrescendo' pattern, ${ }^{14,26}$ has been used to suggest the diagnosis of celiac disease in such cases (as well as in biopsies with only mild intraepithelial lymphocytosis). This distribution pattern, however, also lacks sufficient specificity for diagnosing celiac disease. ${ }^{13,14}$ In the study by Mino and Lauwers ${ }^{13}$ CD3 + tip-intraepithelial lymphocyte scores were only marginally different from the nonceliac disease group with intraepithelial lymphocytosis $(P=0.054)$. These authors, however, pointed out the utility of calculating villus-tip to base intraepithelial lymphocyte ratios to increase the specificity for celiac disease.

Our findings demonstrate that the spectrum of duodenal intraepithelial lymphocyte distribution patterns in patients with $H$. pylori gastritis overlaps to quite a considerable extent with the patterns described for celiac disease, in agreement with the observations of Goldstein. ${ }^{26}$ Interestingly, in both the studies of Goldstein and Underhill ${ }^{14}$ and Mino and Lauwers, ${ }^{13}$ the non-gluten-sensitive groups with increased intraepithelial lymphocytes, included patients with $H$. pylori gastritis. Mahadeva et $a l^{25}$ observed intraepithelial lymphocyte elevations in 14/626 (2.2\%) of consecutive duodenal biopsies with a normal villous architecture over a 12-month period. Celiac disease was discovered in a minority of their cases but no etiology could be determined in $8 / 14(57 \%)$ biopsies. Kakar et $a l^{15}$ observed a significant association of isolated intraepithelial lymphocytosis with a variety of immunological diseases, including Hashimoto's thyroiditis, Graves' disease, rheumatoid arthritis, psoriasis and multiple sclerosis, and NSAID use (in addition to celiac disease). Both these studies, however, did not report any patients with $H$. pylori gastritis. This could relate to the more stringent criteria employed in these studies; only inclusion of biopsies with a generalized intraepithelial lymphocytosis in the former study and a high 'normal' cutoff value for intraepithelial lymphocytes (>40 lymphocytes/100 epithelial cells) in the latter.

The 'normal' range of intraepithelial lymphocytes in the duodenal mucosa has not been well established. Many studies cite the upper limit of normal as 40 lymphocytes/100 epithelial cells, based on the 'normal' range of 6-40 lymphocytes/100 epithelial cells published by Ferguson and Murray ${ }^{34}$ in 1971. It is pertinent to point out that in this study (1) the normal range of intraepithelial lymphocytes was established for the jejunum (not the duodenum), (2) using capsule biopsies (a procedure no longer performed) and (3) numerous diseases/conditions associated with small bowel intraepithelial lymphocytosis were not known at that time. Other reports have used counts > 30 lymphocytes/100 epithelial cells to 'arbitrarily' define elevations of intraepithelial lymphocytes. ${ }^{35,36}$ Mahadeva et $a 2^{25}$ and Hayat et $a l^{30}$ found substantially lower intraepithelial lymphocytes counts in duodenal biopsies from normal patients; range 2-20 (mean 12.4, s.d. 4.6) and 1.8-26 (mean 11, s.d. 6.8), respectively. Based on their results, $22^{25}$ and 25 lymphocytes/100 duodenal epithelial cells ${ }^{30}$ were suggested as the upper limits of normal (mean +2 s.d.). A count of 20 
lymphocytes/100 epithelial cells was chosen as the upper limit of normal in our study, as we have observed that an increase above this level correlates well with the subjective visual impression of an elevation in intraepithelial lymphocytes (unpublished observations) and because we and others ${ }^{35}$ have observed that not only individuals with latent or treated celiac disease but even symptomatic patients can, at times, present with only mild elevations of intraepithelial lymphocytes (see below). The histologic changes in biopsies from such patients are not sufficient to make the diagnosis of celiac disease according to the established criteria $^{37}$ and the interpretation of these biopsies is further compounded by the fact that serologic tests are often negative at this stage. ${ }^{38,39}$ Mino and Lauwers, ${ }^{13}$ presumably, also used a cutoff of 20 lymphocytes/ 100 epithelial cells for similar reasons. If we use 25 lymphocytes/100 epithelial cells as the upper limit of normal, an increased number of intraepithelial lymphocytes would still be seen in a substantial number $(28 \%)$ of duodenal biopsies from patients with $H$. pylori gastritis (Table 3). Intraepithelial lymphocyte counts $>40 / 100$ epithelial cells were only seen in $4 \%(2 / 50)$ of our patients.

A comparison of duodenal intraepithelial lymphocyte distribution patterns and phenotypes, between patients with $H$. pylori gastritis and celiac disease, was not the intent of our study. Although, in order to assess the range of duodenal intraepithelial lymphocyte counts that can be observed in patients with untreated celiac disease, who have similar ethnic and racial characteristics as the patients with $H$. pylori gastritis, we retrospectively performed intraepithelial lymphocyte counts (using CD3 stained sections) on 38 consecutive duodenal biopsies taken from individuals with newly diagnosed and serologically confirmed celiac disease at our institute (during the same period). Demographics of the celiac disease patients were similar to those of the other study groups (data not shown) and the range of intraepithelial lymphocyte counts was 20-104/100 epithelial cells (mean 48.1). Four $(10 \%)$ of the celiac disease patients had intraepithelial lymphocyte counts between 20 and 25 (two had counts between 26-30 and 32 had counts $>30$ lymphocytes/100 epithelial cells). However, none of these patients had normal villous architecture (partial villous atrophy was present in $36 \%$ and subtotal or total villous atrophy in $64 \%$ of the biopsies). Mino and Lauwers ${ }^{13}$ also reported intraepithelial lymphocyte counts in the range of 20-40/ 100 epithelial cells in $3 / 8(37 \%)$ biopsies from patients with celiac disease that had preserved villous architecture. Thus our observations, in conjunction with those of others, ${ }^{13,15,25}$ further reinforce the fact that a substantial overlap in intraepithelial lymphocyte counts exists, between celiac disease and other diseases/conditions, both at the low as well as at the high end of the range of intraepithelial lymphocytosis. Since it has been observed that $H$. pylori gastritis related intraepithelial lymphocyte elevations decrease in the second part of the duodenum, ${ }^{26}$ jejunal biopsies might be of utility in distinguishing these cases from celiac disease. Gluten challenge might also help identify patients with gluten sensitivity, especially in cases where the biopsies have normal mucosal architecture and only a borderline elevation in intraepithelial lymphocytes. ${ }^{35}$

Intraepithelial lymphocytes, in both our study and comparison groups, were: CD3 + , CD8 + , TIA-1 + , and perforin and granzyme-B (weak, focal) + . This phenotype is consistent with alpha-beta T-cell receptor bearing lymphocytes with 'latent' cytotoxic potential. Lymphocytes with this phenotype represent the predominant intraepithelial lymphocyte population of normal human small intestinal muco$\mathrm{sa}^{40,41}$ and expansions of this subset have been described in giardiasis. ${ }^{42}$ In contrast, duodenal intraepithelial lymphocytes in celiac disease ${ }^{42}$ as well as gastric intraepithelial lymphocytes in celiac disease-associated lymphocytic gastritis ${ }^{43}$ have an 'activated' cytotoxic phenotype, that is, the intraepithelial lymphocytes express perforin and granzyme-B. The presence of activated cytotoxic T cells has been documented in the gastric lamina propria in $H$. pylori gastritis and some cases of NSAIDinduced acute gastritis ${ }^{43,44}$ but we are not aware of any studies that have demonstrated this phenotype of the intraepithelial lymphocytes in $H$. pyloriassociated lymphocytic gastritis. No significant expansions of the CD3 + CD8- subset, representing gamma-delta $\mathrm{T}$ cells or a rare subset of CD8- alphabeta T cells, ${ }^{45}$ were seen in any of the biopsies in our study. Gamma-delta T cells are often expanded in biopsies from patients with active celiac disease, ${ }^{46}$ autoimmune diseases, ${ }^{47}$ and primary B-cell immunodeficiency diseases. ${ }^{55}$

The source of duodenal intraepithelial lymphocytes in $H$. pylori gastritis is not known. Lymphoid aggregates were only seen in a minority $(14 \%)$ of cases and thus an origin of intraepithelial lymphocytes from duodenal mucosa-associated lymphoid tissue (MALT) cannot be proposed with certainty. Since an increase in gastric intraepithelial lymphocytes was not observed in any case of $H$. pylori gastritis, an anterograde spread of gastric intraepithelial lymphocytes cannot be invoked either. In addition, $H$. pylori-induced lymphocytic gastritis tends to be corpus predominant. ${ }^{5}$ T-cell-mediated immune responses against $H$. pylori contribute to gastric pathology; ${ }^{48}$ however, there are no data regarding the specificity of duodenal intraepithelial lymphocytes for $H$. pylori. In contrast to the observations in celiac disease, ${ }^{49}$ we only detected rare MIB-1 + intraepithelial lymphocytes in duodenal biopsies from $H$. pylori+ patients. In conjunction with the absence of $H$. pylori in the duodenum and lack of an activated intraepithelial lymphocyte phenotype, our findings support a passive, perhaps trans-endothelial, migration and accumulation of 
intraepithelial lymphocytes, rather than local antigen-induced proliferation. Water extracts of $H$. pylori have been shown to induce neutrophil adhesion and emigration from rat mesenteric venules $;^{50}$ however, a similar inductive effect has not been described for duodenal lymphocytes. Further studies are required to determine whether antigens shed or secreted by $H$. pylori from the gastric antrum play a role in the epithelial migration of duodenal lymphocytes. Duodenal intraepithelial lymphocytosis has recently been reported in association with NSAID use ${ }^{15}$ and increased intestinal permeability and inflammation have also been documented for certain types of NSAID's. ${ }^{51}$ A history of NSAID use was obtained for only $10 \%$ of our patients with $H$. pylori gastritis and no elevation in duodenal intraepithelial lymphocytes was seen in any of the cases of reactive gastritis. Future studies should investigate the possible roles of the type of NSAID, dosage, or duration of drug exposure, in inducing duodenal intraepithelial lymphocytosis. Lastly, acid-induced injury must also be considered as a possible explanation for intraepithelial lymphocytosis. Hasan et $a l^{29}$ reported normalization of intraepithelial lymphocyte counts $(<10 / 100$ epithelial cells) after treatment with cimetidine. Endoscopic and histologic evidence of acid-induced injury were lacking in the majority of our patients. We could not assess the response of intraepithelial lymphocytes to treatment, as no follow-up biopsies were performed in any of the patients.

Neutrophils are considered the major mediators of duodenal inflammation and epithelial damage and the severity of duodenal injury is determined by interplay between host (cytokine polymorphisms) and bacterial factors (VacA toxin production and presence of the CagA pathogenecity determinant). ${ }^{52}$ The role of $\mathrm{T}$ cells, specifically intraepithelial lymphocytes, in the pathogenesis of duodenal disease is not known. Hasan et al ${ }^{29}$ attributed the duodenal mucosal damage to mediators of acute inflammation and considered the intraepithelial lymphocyte elevations to represent a nonspecific reaction. Since serological markers of celiac disease were only evaluated in four patients (all were negative), we cannot exclude the possibility that a few patients may have had celiac disease. We believe this supposition to be unlikely for the majority of the patients as: (1) all patients responded to the triple drug regimen for $H$. pylori and (2) the incidence of intraepithelial lymphocytosis (44\%) in our study was much higher than the incidence of celiac disease in the US population (approximately $1 \%)^{9}$

The purpose of this study is to alert pathologists to the frequent occurrence of duodenal intraepithelial lymphocyte expansions in individuals with $H$. pylori gastritis and the considerable overlap of the intraepithelial lymphocyte counts as well as the distribution patterns with those described for celiac disease. H. pylori gastritis could be an explanation for duodenal intraepithelial lymphocyte elevations, when duodenal mucosal alterations are absent, lymphocytosis is patchy, and the intraepithelial lymphocytes have a latent cytotoxic profile. Further studies are needed to address the significance of the intraepithelial lymphocyte expansions and the extent to which other variables, such as host susceptibility factors (HLA and non-HLA-associated) and NSAID use, could contribute to this phenomenon.

\section{References}

1 Dunn BE, Cohen H, Blaser MJ. Helicobacter pylori. Clin Microbiol Rev 1997;10:720-741.

2 Vaira D, Holton J, Menegatti M, et al. Routes of transmission of Helicobacter pylori infection. Ital J Gastroenterol Hepatol 1998;30:S279-S285.

3 Lacy BE, Rosemore J. Helicobacter pylori: ulcers and more. J Nutr 2001;131:2789S-2793S.

4 Versalovic J. Helicobacter pylori. Pathology and diagnostic strategies. Am J Clin Pathol 2003;119:403-412.

5 Wu TT, Hamilton SR. Lymphocytic gastritis: association with etiology and topology. Am J Surg Pathol 1999;23:153-158.

6 Gisbert JP, Blanco M, Cruzado AI, et al. Helicobacter pylori infection, gastric metaplasia in the duodenum and the relationship with ulcer recurrence. Eur J Gastroenterol Hepatol 2000;12:1295-1298.

7 Suriani R, Venturini I, Actis GC, et al. Effect of Helicobacter pylori eradication on bulbitis and duodenal gastric metaplasia. Hepatogastroenterology 2004; 51:176-180.

8 Ciclitira PJ, King AL, Fraser JS. AGA technical review on Celiac Sprue. American Gastroenterological Association. Gastroenterology 2001;120:1526-1540.

9 Green PH, Jabri B. Celiac disease. Lancet 2003;362: 383-391.

10 Marsh MN, Crowe PT. Morphology of the mucosal lesion in gluten sensitivity. Baillieres Clin Gastroenterol 1995;9:273-293.

11 Kaukinen K, Maki M, Partanen J, et al. Celiac disease without villous atrophy: revision of criteria called for. Dig Dis Sci 2001;46:879-887.

12 Picarelli A, Maiuri L, Mazzilli MC, et al. Glutensensitive disease with mild enteropathy. Gastroenterology 1996;111:608-616.

13 Mino M, Lauwers GY. Role of lymphocytic immunophenotyping in the diagnosis of gluten-sensitive enteropathy with preserved villous architecture. Am J Surg Pathol 2003;27:1237-1242.

14 Goldstein NS, Underhill J. Morphologic features suggestive of gluten sensitivity in architecturally normal duodenal biopsy specimens. Am J Clin Pathol 2001;116:63-71.

15 Kakar S, Nehra V, Murray JA, et al. Significance of intraepithelial lymphocytosis in small bowel biopsy samples with normal mucosal architecture. Am J Gastroenterol 2003;98:2027-2033.

16 Day DW, Jass JR, Price AB, et al. Morson and Dawson's Gastrointestinal Pathology. Blackwell Publishing: Oxford, 4th edn. 2003.

17 Dixon MF, Genta RM, Yardley JH, et al. Classification and grading of gastritis. The updated Sydney System. International Workshop on the Histopathology of 
Gastritis, Houston 1994. Am J Surg Pathol 1996;20:1161-1181.

18 Scoglio R, Di Pasquale G, Pagano G, et al. Is intestinal biopsy always needed for diagnosis of celiac disease? Am J Gastroenterol 2003;98:1325-1331.

19 Fry L, Seah PP, McMinn RM, et al. Lymphocytic infiltration of epithelium in diagnosis of glutensensitive enteropathy. BMJ 1972;3:371-374.

20 Leigh RJ, Marsh MN, Crowe P, et al. Studies of intestinal lymphoid tissue. IX. Dose-dependent, gluten-induced lymphoid infiltration of coeliac jejunal epithelium. Scand J Gastroenterol 1985;20:715-719.

21 Anand BS, Piris J, Jerrome DW, et al. The timing of histological damage following a single challenge with gluten in treated coeliac disease. Q J Med 1981;50: 83-94.

22 Holmes GK. Potential and latent coeliac disease. Eur J Gastroenterol Hepatol 2001;13:1057-1060.

23 Oxentenko AS, Murray JA. Celiac disease and dermatitis herpetiformis: the spectrum of gluten-sensitive enteropathy. Int J Dermatol 2003;42:585-587.

24 Gudjonsdottir AH, Nilsson S, Ek J, et al. The risk of celiac disease in 107 families with at least two affected siblings. J Pediatr Gastroenterol Nutr 2004;38:338-342.

25 Mahadeva S, Wyatt JI, Howdle PD. Is a raised intraepithelial lymphocyte count with normal duodenal villous architecture clinically relevant? J Clin Pathol 2002;55:424-428.

26 Goldstein NS. Proximal small-bowel mucosal villous intraepithelial lymphocytes. Histopathology 2004;44: 199-205.

27 Shah VH, Rotterdam H, Kotler DP, et al. All that scallops is not celiac disease. Gastrointest Endosc 2000;51:717-720.

28 Goldstein NS. Non-gluten sensitivity-related small bowel villous flattening with increased intraepithelial lymphocytes: not all that flattens is celiac sprue. Am J Clin Pathol 2004;121:546-550.

29 Hasan M, Hay F, Sircus W, et al. Nature of the inflammatory cell infiltrate in duodenitis. J Clin Pathol 1983;36:280-288.

30 Hayat M, Cairns A, Dixon MF, et al. Quantitation of intraepithelial lymphocytes in human duodenum: what is normal? J Clin Pathol 2002;55:393-394.

31 Siegel LM, Stevens PD, Lightdale CJ, et al. Combined magnification endoscopy with chromoendoscopy in the evaluation of patients with suspected malabsorption. Gastrointest Endosc 1997;46:226-230.

32 Vogelsang H, Hanel S, Steiner B, et al. Diagnostic duodenal bulb biopsy in celiac disease. Endoscopy 2001;33:336-340.

33 Dickey W, Hughes D. Prevalence of celiac disease and its endoscopic markers among patients having routine upper gastrointestinal endoscopy. Am J Gastroenterol 1999;94:2182-2186.

34 Ferguson A, Murray D. Quantitation of intraepithelial lymphocytes in human jejunum. Gut 1971;12:988-994.

35 Wahab PJ, Crusius BA, Meijer JWR, et al. Gluten challenge in borderline gluten-sensitivity enteropathy. Am J Gastroenterol 2001;96:1464-1469.

36 Lee SK, Lo W, Memeo L, et al. Duodenal histology in patients with celiac disease after treatment with a gluten-free diet. Gastrointest Endosc 2003;57:187-191.

37 Walker-Smith JA. Management of infantile gastroenteritis. Arch Dis Child 1990;65:909-911.

38 Rostami K, Kerckhaert J, Tiemessen R, et al. Sensitivity of antiendomysium and antigliadin antibodies in untreated celiac disease: disappointing in clinical practice. Am J Gastroenterol 1999;94:888-894.

39 Cataldo F, Ventura A, Lazzari L, et al. Antiendomysium antibodies and coeliac disease: solved and unsolved questions. An Italian multicentre study. Acta Paediatr 1995;84:1125-1131.

40 Russell GJ, Nagler-Anderson C, Anderson P, et al. Cytotoxic potential of intraepithelial lymphocytes (IELs). Presence of TIA-1, the cytolytic granuleassociated protein, in human IELs in normal and diseased intestine. Am J Pathol 1993;143:350-354.

41 Chott A, Gerdes D, Spooner A, et al. Intraepithelial lymphocytes in normal human intestine do not express proteins associated with cytolytic function. Am J Pathol 1997;151:435-442.

42 Oberhuber G, Vogelsang H, Stolte M, et al. Evidence that intestinal intraepithelial lymphocytes are activated cytotoxic $\mathrm{T}$ cells in celiac disease but not in giardiasis. Am J Pathol 1996;148:1351-1357.

43 Oberhuber G, Bodingbauer M, Mosberger I, et al. High proportion of granzyme B-positive (activated) intraepithelial and lamina propria lymphocytes in lymphocytic gastritis. Am J Surg Pathol 1998;22: 450-458.

44 Suzuki T, Ito M, Hayasaki N, et al. Cytotoxic molecules expressed by intraepithelial lymphocytes may be involved in the pathogenesis of acute gastric mucosal lesions. J Gastroenterol 2003;38:216-221.

45 Hayday A, Theodoridis E, Ramsburg E, et al. Intraepithelial lymphocytes: exploring the Third Way in immunology. Nat Immunol 2001;2:992-1003.

46 Jarvinen TT, Kaukinen K, Laurila K, et al. Intraepithelial lymphocytes in celiac disease. Am J Gastroenterol 2003;98:1332-1337.

47 Brandtzaeg P, Farstad IN, Helgeland L. Phenotypes of T cells in the gut. Chem Immunol 1998;71:1-26.

48 D'Elios MM. Helicobacter pylori antigen-specific T-cell responses at gastric level in chronic gastritis, peptic ulcer, gastric cancer and low-grade mucosa-associated lymphoid tissue (MALT) lymphoma. Microbes Infection 2003;5:723-730.

49 Halstensen TS, Brandtzaeg P. Activated T lymphocytes in the celiac lesion: non-proliferative activation (CD25) of CD4+ alpha/beta cells in the lamina propria but proliferation (Ki-67) of alpha/beta and gamma/delta cells in the epithelium. Eur J Immunol 1993;23: 505-510.

50 Yoshida N, Granger DN, Evans DJ, et al. Mechanisms involved in Helicobacter pylori-induced inflammation. Gastroenterology 1999;105:1431-1440.

51 Sigthorsson G, Tibble J, Hayllar J, et al. Intestinal permeability and inflammation in patients on NSAIDs. Gut 1998;43:506-511.

52 Walker MM, Crabtree JE. Helicobacter pylori infection and the pathogenesis of duodenal ulceration. Ann NY Acad Sci 1998;859:96-111.

53 Mavromichalis J, Brueton MJ, McNeish AS, et al. Evaluation of the intraepithelial lymphocyte count in the jejunum in childhood enteropathies. Gut 1976;17: 600-603.

54 Klemola T. Immunohistochemical findings in the intestine of IgA-deficient persons: number of intraepithelial $\mathrm{T}$ lymphocytes is increased. J Pediatr Gastroenterol Nutr 1988;7:537-543.

55 Nilssen DE, Halstensen TS, Froland SS, et al. Distribution and phenotypes of duodenal intraepithelial gamma/delta $\mathrm{T}$ cells in patients with various types of 
primary B-cell deficiency. Clin Immunol Immunopathol 1993;68:301-310.

56 Burrows PJ, Fleming JS, Garnett ES, et al. Clinical evaluation of the $14 \mathrm{C}$ fat absorption test. Gut 1974;15: 147-150.

57 Ansari A. Nontropical and tropical duodenal mucosa. Am J Gastroenterol 2003;98:501-502.

58 Wright CL, Riddell RH. Histology of the stomach and duodenum in Crohn's disease. Am J Surg Pathol 1998; 22:383-390.
59 Tornblom H, Lindberg G, Nyberg B, et al. Fullthickness biopsy of the jejunum reveals inflammation and enteric neuropathy in irritable bowel syndrome. Gastroenterology 2002;123:1972-1979.

60 Holden W, Orchad T, Woodsworth P. Enteropathic arthritis. Rheum Dis Clin North Am 2003;3:513-530.

61 Cutz E, Sherman PM, Davidson GP. Entheropaties associated with protracted diarrhea of infancy: clinicopathologic features, cellular and molecular mechanisms. Pediatr Pathol Lab Med 1997;17:335-368. 